\title{
Coal fly ash as a potential fixation reagent for radioactive wastes
}

\author{
Roy Nir Lieberman ${ }^{\mathrm{a}, \mathrm{b}, *}$, Uri Green ${ }^{\mathrm{a}}$, Giora Segev ${ }^{\mathrm{a}, \mathrm{c}}$, Mehmet Polat ${ }^{\mathrm{d}}$, Yitzhak Mastai ${ }^{\mathrm{b}}$, Haim Cohen ${ }^{\mathrm{a}, \mathrm{e}, *}$ \\ a Department of Biological Chemistry, Ariel University at Samaria, Ariel 40700, Israel \\ ${ }^{\mathrm{b}}$ Department of Chemistry and the Institute of Nanotechnology, Bar-Ilan University, Ramat-Gan, Israel \\ ${ }^{\mathrm{C}}$ Israel Atomic Energy Commission, Tel-Aviv, Israel \\ ${ }^{\mathrm{d}}$ Department of Chemical Engineering, Izmir Institute of Technology, Turkey \\ ${ }^{\mathrm{e}}$ Chemistry Department, Ben-Gurion University of the Negev, Beer Sheva, Israel
}

\section{H I G H L I G H T S}

- Fly-ash acts as a blocking barrier for radionuclide cations diffusion.

- Fixation of the radionuclides is via $-\mathrm{AlO}_{2}{ }^{-} /-\mathrm{SiO}_{3}{ }^{-}$anions at the fly ash surface.

- A novel $\mathrm{Sr}^{90}$ fixation mode via precipitation and adsorption to the fly ash is found.

\section{A R T I C L E I N F O}

\section{Article history:}

Received 19 January 2015

Received in revised form 23 February 2015

Accepted 24 February 2015

Available online 9 March 2015

\section{Keywords:}

Fly ash

Radioactive

Waste

Fixation

Carbonate

\begin{abstract}
A B S T R A C T
Israel produces $\sim 1.3 \mathrm{Mt} / \mathrm{year}$ of fly ash (FA), a byproduct of its coal-fired power plants. Due to increasing environmental regulations, these imported coals are processed to reduce the sulfur concentration ( $\sim 0.6 \%)$. These processing methods result in a material that has an enriched alkali/alkali earth component with pozzolanic and basic properties $(\mathrm{pH}>10.5)$.

FAs are utilized worldwide, mainly as a cement additive for the construction industry. Recently, it was demonstrated that Class F FA can act as an excellent fixation reagent for acidic wastes from the phosphate or the oil regeneration industries. In the current work the potential utilization of Class F FAs as fixation reagents for low-activity radioactive waste from the nuclear industry was examined. Aqueous solutions containing radionuclide simulants: cesium $\left(\mathrm{Cs}^{+}\right)$, strontium, $\left(\mathrm{Sr}^{2+}\right)$, and cerium $\left(\mathrm{Ce}^{3+}, \mathrm{Ce}^{4+}\right)$ were used as case studies with promising results. It is suggested that the primary fixation mechanism involves the aluminate/silicate anions at the FA surface. A novel experimental fixation approach utilizing the formation of carbonates is demonstrated and a new interaction mechanism is suggested based on the electrostatic interactions of the positively charged fine precipitates with the negatively charged FA surface.
\end{abstract}

(c) 2015 Elsevier Ltd. All rights reserved.

\section{Introduction}

Israel utilizes imported bituminous coal as a primary fossil fuel for power production ( $>63 \%$ in 2013 [1]). Annually, the utilities consume $\sim 13 \mathrm{Mt}$ of coal producing 183,000 tons of bottom ash (BA) and 1.3 Mt of FA [2]. The coals are imported mainly from South Africa but also from Colombia, Australia, Indonesia, and Russia [2] and contain $\sim 10 \%$ of inorganic mineral materials.

In line with Israel's strict environmental regulations regarding the emission of pollutants to air via the combustion process [3], the imported coal undergoes beneficiation (via washing with

\footnotetext{
* Corresponding authors at: Department of Biological Chemistry, Ariel University at Samaria, Ariel 40700, Israel. Tel.: +972 54 7776499; fax: +972 89200749.

E-mail addresses: roynl@ariel.ac.il (R.N. Lieberman), hcohen@ariel.ac.il (H. Cohen).
}

water) to reduce the organic constituents; primarily sulfur (S) and phosphorous (P) [4] and some trace elements (e.g. $\mathrm{Hg}, \mathrm{Pb}$, and As). The result is that the FA produced is rich in alkali and alkali earth elements, pozzolanic with cementitious properties, and is considered to be a Class F FA [2] (which has a basic solution in contact with water). Consequently, when in contact with water, the FA is highly basic, $\mathrm{pH}>10.5$ at Solid /Liquid ratio of $1 / 10$, due to high lime content $(\mathrm{CaO})$ in the FA. Currently, $100 \%$ of the ash (bottom and fly) produced [2] in Israel is utilized in the construction industry either as a cement additive (up to $10 \%$ weight content), road structural filler, or other minor applications (e.g. agriculture) $[2,5-15]$. Thus, it is economic value is rather low $\leqslant 15 \$ /$ ton.

The possibility of using FA as an effective neutralization and fixation reagent for acidic wastes has been explored and suggested as a more significant economic value added as a utilization method [16-19]. 
Several mechanisms for the fixation of metal ions and the FA surface have been previously suggested [20-23].

\subsection{Cation-exchange}

The surface of the FA particles contains several anionic functional groups mainly aluminates $-\mathrm{O}-\mathrm{AlO}^{-}$and silicates $-\mathrm{O}-\mathrm{SiO}_{2}^{-}$: which can behave as a cation-exchange material. Typical metal cations that can undergo fixation to the FA surface are mono- or divalent metal cations (e.g., $\mathrm{Cs}^{+}, \mathrm{Cd}^{2+}, \mathrm{Cu}^{2+}$, and $\mathrm{Sr}^{2+}$ ).

\subsection{Coordinative bonding}

Coordinative bonding is formed between the cation and nonbonding electrons of functional groups located at the surface of the FA particles. The cation behaves as a Lewis acid and the FA surface behaves as a Lewis base. This is a mechanism in which the Lewis base donating the lone pair of electrons forms a bond with the metal cation. This interaction is equivalent to the formation of a complex where the surface groups are the ligands. Energetically, it is a relatively strong bond, which can reach a strength of $>150 \mathrm{~kJ} / \mathrm{mol}$ [24]. Typical metal cations that can undergo this interaction are $\mathrm{Ce}^{\mathrm{III}}, \mathrm{Ce}^{\mathrm{IV}}$, or $\mathrm{UO}_{2}^{2+}$ ).

The feasibility of this application has also been effectively demonstrated with industrial wastes. The acidic organic waste produced during regeneration processes of used motor oil (via Oleum extraction) yields extremely acidic waste, $>10 \mathrm{M} \mathrm{H}^{+}$with a high concentration of heavy and toxic metals [17] along with the acidic waste $(0.1-1 \mathrm{M})$ from the phosphate industry (a byproduct of the phosphate rock dissolution process via either sulfuric or hydrochloric acids [16] were both effectively neutralized with a FA fixation method. In both types of wastes (motor oil and phosphate), fixation with FA produces a grey sand-like aggregate. The effectiveness of the toxic and heavy metal content fixation was determined using European Directive [25], the USEPA TCLP 1311 [26], and CALWET [27] leaching procedures. Furthermore, the leaching of trace elements from the scrubbed product is within the Israeli drinking limits criteria [28].

These initial findings demonstrated fixation of acidic and heavy metals in Class F FAs and therefore have the potential ability to reduce the costs of low activity radioactive wastes treatment produced in the nuclear energy industry.

Unlike other industrial wastes, the hazard level of all nuclear waste - its radioactivity - diminishes with time. Each radionuclide contained in the waste has a half-life - the time taken for half of its atoms to decay, and, thus for it to lose half of its radioactivity (assuming that the product of decay are not radioactive by themselves). The half-life of radionuclides can vary from seconds to millions of years (see below). Radionuclides with long half-lives tend to be alpha and beta emitters - making their handling easier while those with short half-lives tend to emit the more penetrating gamma rays. Eventually all radioactive wastes decay into non-radioactive elements. The more radioactive an isotope is, the faster it decays.

The main objective in managing and disposing of radioactive (or other) waste is to protect people and the environment. This means isolating or diluting the waste so that the rate or concentration of any radionuclides returned to the biosphere is harmless. To achieve this, practically all wastes are contained and managed some clearly need deep and permanent burial. From nuclear power generation, none is allowed to cause harmful pollution. High-level wastes, which contain $19 \%$ of the total activity of accumulated liquid radioactive wastes, are the most dangerous. The activity of high-level wastes is determined by the high concentrations of isotopes ${ }^{137} \mathrm{Cs},{ }^{134} \mathrm{Cs}$, and ${ }^{90} \mathrm{Sr}$, as well as by the presence of long-lived actinides. The ecological risk due to intermediate-level wastes is associated with the fact that the activity of these wastes comprises the main fraction of the total activity of all accumulated liquid radioactive wastes. [29].

FA has demonstrated fixation properties and has the potential to reduce storage and treatment costs of various wastes. It can also potentially service the nuclear industry by partially substituting other storage materials (concrete, bitumen), which are currently utilized. The current work focuses on the ability of the FA to fixate the following types of radionuclides occurring in typical radioactive wastes [30-34]:

(i) $\mathbf{C s}^{\mathbf{1 3 7}}$ is one of the main nuclear fission byproducts of $\mathbf{U}^{\mathbf{2 3 5}}$ in nuclear power plants (with a half-life of 30.17 years [31]). This radionuclide decays via emission of $\beta$ rays $(0.19 \mathrm{MeV})$ to form metastable nucleus of Barium $(137 \mathrm{~m})-\mathbf{B a}^{\mathbf{1 3 7 m}}$, which further decays relatively fast $(2.6 \mathrm{~min})$ via emission of $\gamma$ rays $(0.60 \mathrm{MeV})$ to the stable isotope of Barium $\mathbf{B a}^{\mathbf{1 3 7}}$.

(ii) $\mathbf{S r}^{\mathbf{9 0}}$ This radionuclide is also one of the major nuclear fission byproducts of $\mathbf{U}^{\mathbf{2 3 5}}$. Its half-life is 28.90 years [30] and it decays via $\beta$ irradiation emission $(0.546 \mathrm{MeV})$ to a stable isotope of Yttrium $\mathbf{Y}^{\mathbf{9 0}}$.

These two radionuclides have a medium half-life and have to be stored for centuries until decaying to a low-level background radiation.

(iii) Actinides The Actinides, which are one of the main byproducts during fission, are all radioactive. They are usually formed via neutron capture by $U$ isotopes (mainly $\mathbf{U}^{\mathbf{2 3 8}}$ ) and have relatively very long half-lives. These actinides are f-block elements, filling the $5 f$ electron shell and are also $\alpha$ emitters. Typical actinides are the plutonium - Pu or Americium - Am [35].

\section{Experimental}

\subsection{Fly ash characterization}

The FA used in the current study is the combustion waste product from South African (SA) and Colombian (CO) coals used in Israel and were supplied by the Israeli Electricity Company. In this paper, the two FA types will hereby be referred to (adding a SA or CO prefix) as SAFA or COFA. The SA and CO coals after beneficiation contain $13.9 \mathrm{wt} . \%$ and $8.7 \mathrm{wt} . \%$ ash and have a spatial density of $0.98 \mathrm{~g} / \mathrm{cm}^{3}$ and $0.85 \mathrm{~g} / \mathrm{cm}^{3}$, respectively. The ambient air quality standards used in Israel require a low content of $S$ and $P$ in the combustion process. The FA product of these pretreated coals leads to the enrichment of the ash with alkali and alkali earth elements, mainly Ca. The FA particles $[11,36]$ are spherical and have a diameter of between 3 and $250 \mu \mathrm{m}$ (Fig. 1). Moreover, XRD analysis was performed on both the SAFA and the COFA (Fig. S1).

The FA mainly contains two different types of spherical particles. Cenospheres (Fig. 1C) are hollow "glass bubbles" [37] of aluminosilicates. These particles also contain carbon dioxide or nitrogen which give the ash lightweight properties [37-39]. The second type are the Pleurospheres [40] (Fig. 1D) which are "hollow glass bubbles" filled with smaller glassy particles. In addition, some minerals such as spinels are also present within the FA [41]. FA particles have a relatively large surface area for a non-porous material [2] (1.05 $\pm 0.1 \mathrm{~m}^{2} / \mathrm{g}$ for SAFA and COFA). The averaged chemical analysis of both the SAFA and COFA is presented in Table 1.

EDAX analysis of the FA surface functionality presented in Fig. 1 show that SAFA and COFA have similar concentrations (surface coverage) of Si and Al. 

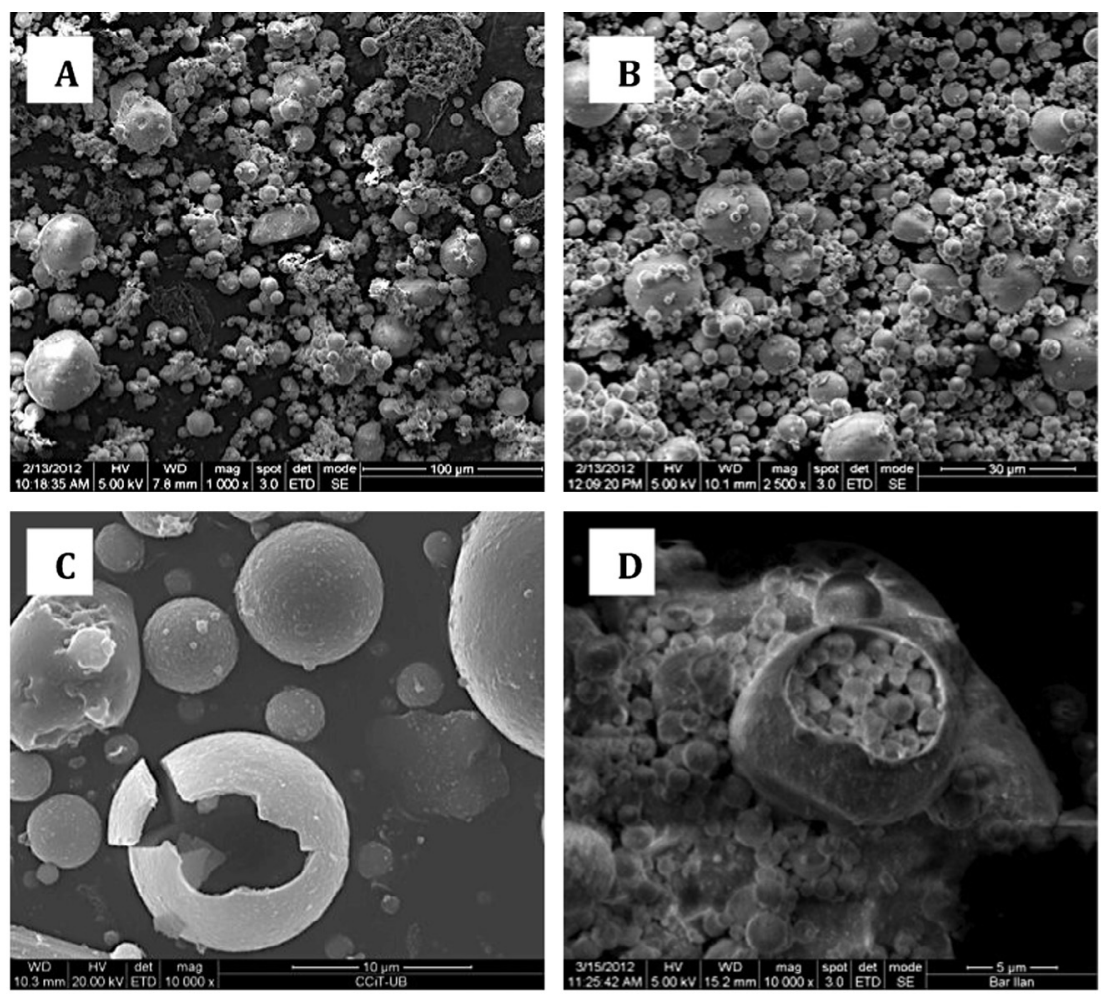

\begin{tabular}{llllllllllll}
\hline Wt.\% & O & Al & Si & Na & Mg & P & K & Ca & Ti & Fe & Total \\
\hline SAFA (image A) & 49.0 & 17.8 & 24.4 & 0.4 & 1.1 & 0.7 & 0.4 & 4.0 & 0.7 & 1.5 & 100 \\
COFA (image B) & 41.0 & 17.1 & 27.0 & 4.7 & 1.2 & N.A. & 2.2 & 2.1 & 0.9 & 3.8 & 100 \\
\hline
\end{tabular}

** error factor $\pm 0.1 \%$

Fig. 1. SEM images of: (a) South African fly ash, (b) Colombian fly ash, (c) South African fly ash cenospheres and (d) Colombian fly ash Pleurospheres.

Table 1

Chemical composition of major (wt.\%) and trace elements (mg/kg) of South African fly ash and Colombian fly ash. ${ }^{\text {a }}$

\begin{tabular}{|c|c|c|c|c|c|c|c|c|c|c|c|c|c|c|c|}
\hline Major elements & $\mathrm{SiO}_{2}$ & $\mathrm{Al}_{2} \mathrm{O}_{3}$ & $\mathrm{TiO}_{2}$ & $\mathrm{Fe}_{2} \mathrm{O}_{3}$ & $\mathrm{CaO}$ & & $\mathrm{MgO}$ & & $\mathrm{K}_{2} \mathrm{O}$ & & $\mathrm{Na}_{2} \mathrm{O}$ & $\mathrm{P}_{2} \mathrm{O}_{5}$ & $\mathrm{SO}_{3}$ & $\mathrm{LOI}^{\mathrm{b}}$ & Total \\
\hline SAFA & 41 & 31 & 1.6 & 3.1 & 9.5 & & 2.2 & & 0.8 & & 0.2 & 2.4 & 0.7 & 5.0 & 97.5 \\
\hline COFA & 56 & 23 & 1.0 & 7.1 & 3.4 & & 1.7 & & 1.6 & & 3.1 & 0.3 & 0.9 & 2.3 & 100.4 \\
\hline Trace elements & $\mathrm{Ag}$ & As & $\mathrm{Ba}$ & $\mathrm{Be}$ & $\mathrm{Cd}$ & Co & & $\mathrm{Cr}$ & & $\mathrm{Cu}$ & Mn & $\mathrm{Ni}$ & $\mathrm{Sr}$ & $\mathrm{Hg}$ & $\mathrm{Pb}$ \\
\hline SAFA & 14 & $<10$ & 2,160 & 9.43 & $<2$ & 40 & & 150 & & 77 & 440 & 68 & 3,250 & 0.4 & 80 \\
\hline COFA & 9.5 & $<10$ & 3,210 & 5.07 & 2 & 27 & & 133 & & 60 & 330 & 70 & 1,050 & 0.2 & 78 \\
\hline
\end{tabular}

${ }^{a}$ Both Fly ashes were homogenized, several analyses were carried out for each fly ash.

${ }^{\mathrm{b}} \mathrm{LOI}=$ loss on ignition.

In line with the average chemical composition (Table 1), the XRD bulk analysis of the FA presented in Fig. S1 shows that the primary minerals present in both types of ash are Mullite $\left(3 \mathrm{Al}_{2} \mathrm{O}_{3}-\right.$ $\left.2 \mathrm{SiO}_{2}\right)$ and Quartz $\left(\mathrm{SiO}_{2}\right)$.

Moreover, the bulk Quartz/Mullite ratio is different for either FA. In the SAFA, Mullite is the dominant mineral while COFA has more Quartz. Surprisingly, despite this difference in the bulk composition, the EDAX results (Fig. 1) seem to indicate (within the experimental error) that surface content of these two elements (in the COFA and SAFA) is similar. The high concentration of $\mathrm{Al}$ and $\mathrm{Si}$ at the surface is present in the form of aluminate and silicate groups.

Finally, these surface groups (aluminates and silicates) have a significant negative surface charge, which is confirmed by measuring the zeta potential. The results from the zeta potential analysis at basic pHs are presented in Fig. 2.

\subsection{Chemicals}

Due to the high cost of operation when working with radionuclides, accepted simulants utilized in nuclear research were selected for these studies. The following four simulants, $\mathrm{Cs}^{133}$ as simulant to the radionuclide $\mathrm{Cs}^{137}, \mathrm{Sr}^{88}$ as simulant to the radionuclide $\mathrm{Sr}^{90}$, and $\mathrm{Ce}^{3+}$ and $\mathrm{Ce}^{4+}$ as simulants to the Actinide group were selected after consulting with researchers from the Nuclear Research Center Negev (NRCN). The simulants salts chosen were $\mathrm{CsNO}_{3}, \mathrm{Sr}\left(\mathrm{NO}_{3}\right)_{2}, \mathrm{Ce}\left(\mathrm{NO}_{3}\right)_{3}$, and $\left.\mathrm{Ce}\left(\mathrm{SO}_{4}\right)_{2} \cdot 2\left(\mathrm{NH}_{4}\right)_{2} \mathrm{SO}_{4}: 2 \mathrm{H}_{2} \mathrm{O}\right)$. All salts used were analytical grade and purchased from Sigma/ 

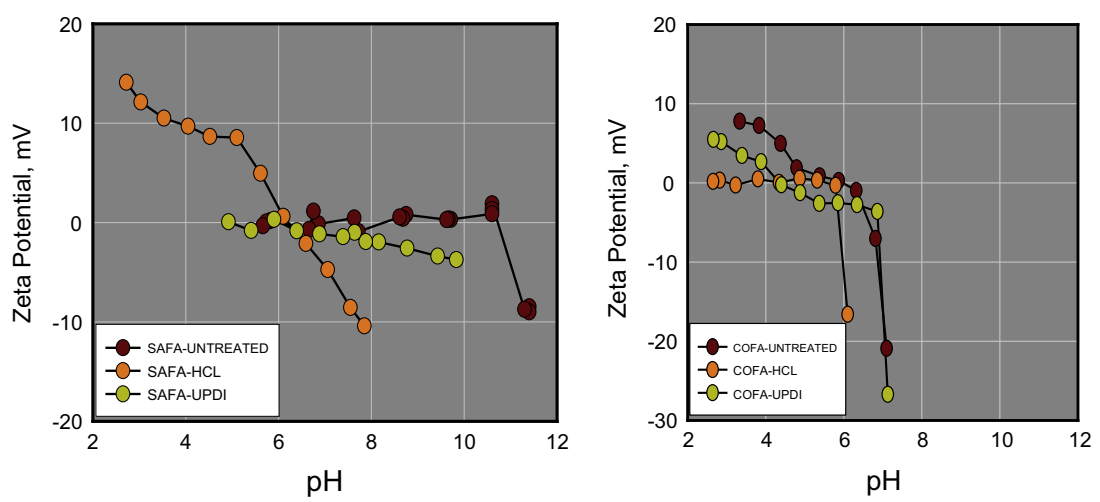

Fig. 2. Zeta potential measurements of untreated/treated South African fly ash/Colombian fly ash.

Aldrich or Merck. Water used in the study was DDW (Double Distilled Water) using a Tri-ion system with a measured resistance larger than $10 \mathrm{Mohms} / \mathrm{cm}$.

\subsection{Analytical methods}

Solution concentrations of $\mathrm{Sr}^{2+}, \mathrm{Cs}^{+}, \mathrm{Ce}^{3}$, and $\mathrm{Ce}^{4+}$ were determined with Inductively-Coupled Plasma Atomic Emission Spectrometry (ICP-AES) model Thermo Jarrell Ash IRIS as well as Inductively-Coupled Plasma Mass Spectrometry (ICP-MS) model Thermo Electron Corporation X-Series. Ion chromatograph (Dionex model DX-500) was used to determine $\mathrm{Cs}^{+}$concentrations. Six Calibration solutions were prepared from a M-solution (Manufactured by Fischer) of $1000 \mathrm{ppm}$ : $0.05 \mathrm{ppm}, 0.1 \mathrm{ppm}$, $0.5 \mathrm{ppm}, 1 \mathrm{ppm}, 10 \mathrm{ppm}$, and $20 \mathrm{ppm}$. The detection limit was $<0.05 \mathrm{ppm}$ for all simulants. A typical sample for ICP analysis was prepared by passing it through $0.45-\mu \mathrm{m}$ Whatman puradisc FP 30 CA-S filters. After the mixing period, the fly ash was filtered from the slurry and a sample from the solution was taken and acidified with $0.1 \%$ vol. of concentrated $\mathrm{HNO}_{3}$ to prevent precipitation. Finally the concentration of the desired element was analyzed with ICP-AES.

Orbital Shakers from Cocono, model TS-400 were used for the fixation procedure.

Samples composition and morphology was analyzed by a MK2 Quanta 200 Scanning Electron Microscope with energy dispersive $\mathrm{X}$-ray analyzer (SEM-EDAX).

XRD patterns were collected using a Bruker D8 Advance diffractometer with monochromatic $\mathrm{Cu} K \alpha 1,2$ radiation $(\lambda=1.5405)$ operated at $40 \mathrm{KV}$ and $40 \mathrm{~mA}$. The primary parallel X-ray beam was generated by a Göbbel mirror and the scattered beam was analyzed by a Sol-X detector with the following scanning parameters: from $4^{\circ}$ at $60^{\circ}$ of $2 \theta$, a step size of $0.05^{\circ}$, and time per step of $3 \mathrm{~s}$.

Zeta potential measurements were carried out on a Malvern Zeta Sizer Nano ZS. This device employs a combination of laser Doppler velocimetry and phase analysis light scattering (PALS) for measuring the zeta potentials. An automatic titrator was used to adjust the $\mathrm{pH}$.

\subsection{Standard fixation experimental procedure}

A standard fixation protocol [42] was used for the fixation experiments. The experimental protocol contains the following four stages:

I. A simulant solution standard was prepared of the trace element ( $\mathrm{Ce}, \mathrm{Sr}$, or $\mathrm{Cs}$ ). The volume was calculated to be sufficient for 25 experiments to reduce standard preparation error. The concentration of each standard was validated by ICP-AES.

II. The solution was mixed with SAFA or COFA in a 500-ml PET bottle, using a fixed $\mathrm{S} / \mathrm{L}$ (solid to liquid) ratio.

III. The slurry was then shaken in the orbital shakers at $250 \mathrm{rpm}$ for different periods of time.

IV. Sample collection - the mixed slurry was settled for $15 \mathrm{~min}$, and then a $10 \mathrm{ml}$ sample from the middle of solution was collected. After that, the sample was filtered with $0.45-\mu \mathrm{m}$ filter and acidified with $0.1 \%$ vol. of concentrated $\mathrm{HNO}_{3}$.

\section{Results}

\subsection{Fixation of $\mathrm{Ce}^{3+}$ and $\mathrm{Ce}^{4+}$ with SAFA and COFA/standard fixation} method

Solutions containing 1,19 , or $20 \mathrm{ppm}$ of $\mathrm{Ce}^{3 / 4+}$ ions were prepared from $\mathrm{Ce}\left(\mathrm{NO}_{3}\right)_{3}$ or $\mathrm{Ce}\left(\mathrm{SO}_{4}\right)_{2} \cdot 2\left(\mathrm{NH}_{4}\right)_{2} \mathrm{SO}_{4} \cdot 2 \mathrm{H}_{2} \mathrm{O}$ salts. The solutions were acidified with $\mathrm{HCl}$ to $\mathrm{pH} 2$ in order to avoid reduction of the ions or formation of cerium precipitates [43].

The fixation of the Ce ions was studied as a function of shaking time as shown in Table 2 (samples $1-11\left(\mathrm{Ce}^{3+}\right)$, samples $12-22$ $\left.\left(\mathrm{Ce}^{4+}\right)\right)$.

The $\mathrm{Ce}^{3+/ 4^{+}}$ions were trapped by the FA particles and the concentration of cerium in the $[\mathrm{Ce}]_{\mathrm{f}}$ in the scrubbed solution is below the detection limit. Moreover, the fixation procedure is fast, reaching completion in the course of the first hour.

\subsection{Fixation of $\mathrm{CS}^{+}$with SAFA and COFA/standard fixation methods}

Solutions of 10 or 20 ppm of $\mathrm{Cs}^{+}$ions were prepared from $\mathrm{CsNO}_{3}$ salt. Analysis of $\left[\mathrm{Cs}^{+}\right]$in the filtrate was carried with the ICP-AES spectrometers or with the Dionex ion-chromatograph (Table 3 ).

In all experiments it was found that $\sim 30 \%(0.31 \pm 0.11) \mathrm{Cs}^{+}$ions have been trapped by the FA particles. $[\mathrm{Cs}]_{\mathrm{f}}$ was reduced on average by $5.1 \pm 0.57 \mathrm{ppm}$ regardless of initial concentration.

\subsection{Fixation of $\mathrm{Sr}^{2+}$ with SAFA and COFA/standard fixation methods}

Solutions of $20 \mathrm{ppm}$ of $\mathrm{Sr}^{2+}$ were prepared from $\mathrm{Sr}\left(\mathrm{NO}_{3}\right)_{2}$ salt. The first set of experiments was performed using the same procedure as carried out with the $\mathrm{Cs}^{+}$and $\mathrm{Ce}^{3+, 4+}$ fixation experiments. The filtrate was analyzed for strontium with the ICP-AES spectrometer (Table 4).

The results in Table 4 clearly indicate that there was no of fixation of the $\mathrm{Sr}$ cations. Furthermore, an appreciable amount of $\mathrm{Sr}$ ions leaches out from the FA into the solution (due to the high concentration of the strontium in the SAFA $\sim 0.3 \mathrm{wt} . \%$, Table 1 ). Moreover, in a more acidic environment (either $0.1 \mathrm{M}$ or $1 \mathrm{M}$ 
Table 2

Fixation of $\mathrm{Ce}^{3 / 4+}$ with South African fly ash/Colombian fly ash in a 1:20 ratio S/L $(10 \mathrm{~g} F A: 200 \mathrm{ml}$ solution).

\begin{tabular}{|c|c|c|c|c|c|c|c|c|}
\hline \# & FA type & Ion & FA weight (g) & Shaking period $(\mathrm{h})$ & {$[\mathrm{Ce}]_{0}(\mathrm{ppm})^{\mathrm{a}}$} & {$[\mathrm{Ce}]_{\mathrm{f}}(\mathrm{ppm})^{\mathrm{a}}$} & \% Fixation & $\Delta \mathrm{pH}\left(p \mathrm{H}_{\text {final (afterFAcontact }}-p \mathrm{H}_{\text {initial })}\right.$ \\
\hline 1 & SAFA & $\mathrm{Ce}^{3+}$ & 10 & $10 \mathrm{~min}$ & 19 & 16.3 & $14.2 \%$ & 1.4 \\
\hline 2 & SAFA & $\mathrm{Ce}^{3+}$ & 10 & $30 \mathrm{~min}$ & 19 & 9.5 & $50 \%$ & 1.2 \\
\hline 3 & SAFA & $\mathrm{Ce}^{3+}$ & 10 & 1 & 19 & $<0.05$ & $\sim 100 \%$ & 3.6 \\
\hline 3 & SAFA & $\mathrm{Ce}^{3+}$ & 10 & 5 & 19 & $<0.05$ & $\sim 100 \%$ & 0.3 \\
\hline 4 & SAFA & $\mathrm{Ce}^{3+}$ & 10 & 8 & 19 & 0.9 & $>95 \%$ & 0.4 \\
\hline 5 & SAFA & $\mathrm{Ce}^{3+}$ & 10 & 24 & 19 & $<0.05$ & $\sim 100 \%$ & 0.2 \\
\hline 6 & COFA & $\mathrm{Ce}^{3+}$ & 10 & 5 & 19 & $<0.05$ & $\sim 100 \%$ & 0.6 \\
\hline 7 & COFA & $\mathrm{Ce}^{3+}$ & 10 & 8 & 19 & $<0.05$ & 〜100\% & 0.5 \\
\hline 8 & COFA & $\mathrm{Ce}^{3+}$ & 10 & 24 & 19 & $<0.05$ & $\sim 100 \%$ & 0.7 \\
\hline 9 & SAFA & $\mathrm{Ce}^{3+}$ & 10 & 5 & 1 & $<0.05$ & $\sim 100 \%$ & 0.3 \\
\hline 10 & SAFA & $\mathrm{Ce}^{3+}$ & 10 & 8 & 1 & $<0.05$ & $\sim 100 \%$ & 0.4 \\
\hline \multirow[t]{2}{*}{11} & SAFA & $\mathrm{Ce}^{3+}$ & 10 & 48 & 19 & $<0.05$ & $\sim 100 \%$ & 0.3 \\
\hline & CAL & $\mathrm{Ce}^{3+}$ & 0 & 0 & 19 & 19 & 0 & 1.7 \\
\hline 12 & SAFA & $\mathrm{Ce}^{4+}$ & 10 & $10 \mathrm{~min}$ & 20 & 5.1 & $\sim 75 \%$ & 1.2 \\
\hline 13 & SAFA & $\mathrm{Ce}^{4+}$ & 10 & $30 \mathrm{~min}$ & 20 & 3.7 & $\sim 82 \%$ & 1.8 \\
\hline 14 & COFA & $C e^{4+}$ & 10 & $10 \mathrm{~min}$ & 20 & 6.5 & $\sim 68 \%$ & 0.9 \\
\hline 15 & COFA & $C e^{4+}$ & 10 & $30 \mathrm{~min}$ & 20 & 7.6 & $\sim 62 \%$ & 0.4 \\
\hline 16 & SAFA & $C e^{4+}$ & 20 & 5 & 1 & $<0.05$ & $\sim 100 \%$ & 0.2 \\
\hline 17 & SAFA & $\mathrm{Ce}^{4+}$ & 20 & 24 & 20 & $<0.05$ & $\sim 100 \%$ & 0.5 \\
\hline 18 & SAFA & $C e^{4+}$ & 20 & 96 & 20 & $<0.05$ & $\sim 100 \%$ & 0.4 \\
\hline 19 & SAFA & $\mathrm{Ce}^{4+}$ & 20 & 30 & 1 & $<0.05$ & $\sim 100 \%$ & 0.6 \\
\hline 20 & COFA & $\mathrm{Ce}^{4+}$ & 20 & 48 & 20 & $<0.05$ & $>90 \%$ & 0.5 \\
\hline 21 & COFA & $C \mathrm{e}^{4+}$ & 20 & 72 & 20 & $<0.05$ & 〜100\% & 0.4 \\
\hline \multirow[t]{2}{*}{22} & COFA & $C e^{4+}$ & 20 & 96 & 20 & $<0.05$ & $\sim 100 \%$ & 0.3 \\
\hline & Cal & $\mathrm{Ce}^{4+}$ & 0 & 0 & 20 & 20 & 0 & 1.3 \\
\hline
\end{tabular}

${ }^{*}$ Detection limit $<0.05 \mathrm{ppm}$

${ }^{a}[\mathrm{Ce}]_{0}$ concentration before mixing with FA, $[\mathrm{Ce}]_{\mathrm{f}}$ concentration (after fixation procedure) in the filtrate.

Table 3

Fixation of $\mathrm{Cs}^{+}$with South African fly ash/Colombian fly ash in a 1:20 ratio (S/L).

\begin{tabular}{|c|c|c|c|c|c|c|c|c|}
\hline \# & FA type & FA weight (g) & Shaking period $(\mathrm{h})$ & {$[\mathrm{Cs}]_{0}(\mathrm{ppm})^{\mathrm{a}}$} & {$[\mathrm{Cs}]_{\mathrm{f}}(\mathrm{ppm})^{\mathrm{a}}$} & $\Delta[\mathrm{Cs}]$ & $\%$ Fixation & $\Delta \mathrm{pH}\left(\mathrm{pH}_{\text {final (afterFAcontact }}-\mathrm{pH}_{\text {initial })}\right.$ \\
\hline 1 & COFA & 20 & 1 & 20 & 15.1 & -4.9 & $\sim 25 \%$ & 3.7 \\
\hline 2 & COFA & 20 & 5 & 20 & 15.6 & -4.4 & $22 \%$ & 3.9 \\
\hline 3 & COFA & 20 & 24 & 20 & 14.1 & -5.9 & $\sim 30 \%$ & 3.6 \\
\hline 4 & COFA & 20 & 24 & 10 & 5.3 & -4.7 & $\sim 24 \%$ & 4.1 \\
\hline 5 & COFA & 20 & 24 & 10 & 4.4 & -5.6 & $28 \%$ & 3.7 \\
\hline 6 & SAFA & 20 & 1 & 20 & 14.9 & -5.1 & $\sim 26 \%$ & 5.6 \\
\hline 7 & SAFA & 20 & 5 & 20 & 14.4 & -5.6 & $28 \%$ & 5.8 \\
\hline 8 & SAFA & 20 & 5 & 20 & 15.7 & -4.3 & $\sim 22 \%$ & 5.4 \\
\hline 9 & SAFA & 20 & 24 & 20 & 14.5 & -5.5 & $\sim 28 \%$ & 5.5 \\
\hline 10 & SAFA & 20 & 24 & 10 & 7.2 & -2.8 & $28 \%$ & 5.5 \\
\hline 11 & 0 & 0 & 0 & 20 & 20 & 0 & 0 & 6.0 \\
\hline
\end{tabular}

${ }^{a}[\mathrm{Cs}]_{0}$ concentration before mixing with $\mathrm{FA},[\mathrm{Cs}]_{\mathrm{f}}$ concentration (after fixation procedure) in the filtrate.

Table 4

Fixation of $\mathrm{Sr}^{2+}$ with South African fly ash in a 1:20 ratio (S/L).

\begin{tabular}{|c|c|c|c|c|c|}
\hline \# & SAFA weight (g) & Mixing period $(\mathrm{h})$ & $\begin{array}{l}{[\mathrm{Sr}]_{0}} \\
(\mathrm{ppm})\end{array}$ & $\begin{array}{l}{[\mathrm{Sr}]_{\mathrm{f}}} \\
(\mathrm{ppm})\end{array}$ & \% Fixation \\
\hline 1 & 20 & 5 & 9.9 & 16.8 & $-169 \%$ \\
\hline 2 & 20 & 96 & 9.9 & 34.4 & $-347 \%$ \\
\hline 3 & $20+1 \mathrm{M} \mathrm{HCl}$ & 30 & 9.9 & 551.3 & $\sim-5570 \%$ \\
\hline 4 & $20+0.1 \mathrm{M} \mathrm{HCl}$ & 24 & 9.9 & 16.8 & $-170 \%$ \\
\hline 5 & 0 & 0 & 10 & 9.9 & N.A. \\
\hline
\end{tabular}

* $[\mathrm{Sr}]_{0}$ concentration before mixing with $\mathrm{FA},[\mathrm{Sr}]_{\mathrm{f}}$ concentration (after "fixation" procedure) in the filtrate.

$\mathrm{HCl}$ ) an increased leaching of strontium occurs as a result of dissolution. As the COFA also contains appreciable concentrations of strontium ( $\sim 0.1 \mathrm{wt} . \%$, Table 1$)$, no experiments using this procedure were carried out with the COFA.

\subsection{Fixation of $\mathrm{Sr}^{2+}$ with SAFA and COFA/adapted carbonate fixation method}

In order to utilize FA for the fixation of strontium waste, a different approach is required. A possible method is to precipitate the $\mathrm{Sr}^{2+}$ ions as an insoluble salt and trap it on the surface or in the FA particle pore system. One cost-effective direction is the formation of a carbonate salt; $\mathrm{SrCO}_{3}\left(\mathrm{Ksp}_{(\mathrm{SrCO} 3)}=5.60 \times 10^{-10} \mathrm{M}^{2}\right.$ [44]). In order to precipitate fine $\mathrm{SrCO}_{3}$ particles - strontianite, which might adhere to the surface of the FA particles, three possible methods were investigated:

(i) Addition of $0.5 \mathrm{~g}$ solid sodium carbonate $\left(\mathrm{Na}_{2} \mathrm{CO}_{3}\right)$ to the FA/ $\mathrm{Sr}^{2+}$ solution mixture prior to the fixation process.

(ii) Bubbling of atmospheric air (which contains $\sim 400$ ppm carbon dioxide $-\mathrm{CO}_{2}$ ) through the $\mathrm{FA} / \mathrm{Sr}^{2+}$ solution mixture (as shown in Fig. S2). Since the solution is very basic ( $\mathrm{pH}>10.5$ see above) the $\mathrm{CO}_{2}$ will be trapped in the solution, and will form carbonate anions $\mathrm{CO}_{3}^{2-}$, which subsequently, will precipitate the $\mathrm{Sr}^{2+}$ ions as the carbonate salt.

(iii) Combined addition of $0.5 \mathrm{~g} \mathrm{Na}_{2} \mathrm{CO}_{3}$ and bubbling of atmospheric air $\left(\mathrm{CO}_{2}\right)$ into the $\mathrm{FA} / \mathrm{Sr}^{2+}$ solution.

The precipitation procedure can be summed up by the following set of reactions:

$\mathrm{CO}_{2}+\mathrm{OH}^{-} \rightarrow \mathrm{HCO}_{3(\mathrm{aq})}^{-}$ 
Table 5

Fixation of $\mathrm{Sr}^{2+}$ with FA in a 1:20 ratio $(\mathrm{S} / \mathrm{L})$ as either $\mathrm{Na}_{2} \mathrm{CO}_{3}$ precipitates or air bubbling.

\begin{tabular}{|c|c|c|c|c|c|c|c|c|}
\hline$\#$ & FA type & Carbonate source & FA weight $(\mathrm{g})$ & Mixing period $(\mathrm{h})$ & {$[\mathrm{Sr}]_{0}(\mathrm{ppm})$} & {$[\mathrm{Sr}]_{\mathrm{f}}(\mathrm{ppm})$} & $\%$ Fixation & Final $\mathrm{pH}$ \\
\hline 1 & SAFA & $\mathrm{Na}_{2} \mathrm{CO}_{3}$ addition & 20 & 5 & 9.9 & 0.15 & $\sim 99 \%$ & 12.5 \\
\hline 2 & SAFA & $\mathrm{Na}_{2} \mathrm{CO}_{3}$ addition & 20 & 5 & 9.9 & 0.15 & $\sim 99 \%$ & 12.6 \\
\hline 3 & SAFA & Air bubbling & 20 & 24 & 9.9 & 0.16 & $\sim 99 \%$ & 12.6 \\
\hline 4 & SAFA & Air bubbling & 20 & 24 & 9.9 & 0.12 & $\sim 99 \%$ & 12.4 \\
\hline 5 & SAFA & Air bubbling $+\mathrm{Na}_{2} \mathrm{CO}_{3}$ addition & 10 & 5 & 13.8 & $<0.5$ & $\sim 96 \%$ & 12.7 \\
\hline 6 & COFA & Air bubbling $+\mathrm{Na}_{2} \mathrm{CO}_{3}$ addition & 10 & 5 & 13.8 & 1.0 & $\sim 93 \%$ & 10.7 \\
\hline 7 & N.A. & Air bubbling & 0 & 24 & 10 & 9.9 & N.A. & 12.5 \\
\hline 8 & N.A. & Air bubbling & 0 & 24 & 13.8 & 13.8 & N.A. & 12.4 \\
\hline 9 & N.A. & $\mathrm{Na}_{2} \mathrm{CO}_{3}$ addition & 0 & 5 & 10 & 9.9 & N.A & 12.5 \\
\hline
\end{tabular}

${ }^{*}[\mathrm{Sr}]_{0}$ concentration before mixing with $\mathrm{FA},[\mathrm{Sr}]_{\mathrm{f}}$ concentration after mixing with FA.

${ }^{* *}$ Detection limit $<0.5 \mathrm{ppm}$.

$$
\begin{aligned}
& \mathrm{CO}_{2}+2 \mathrm{OH}^{-} \rightarrow \mathrm{CO}_{3(\mathrm{aq})}^{2-}+\mathrm{H}_{2} \mathrm{O} \\
& \mathrm{Sr}_{(\mathrm{aq})}^{2+}+\mathrm{HCO}_{3(\mathrm{aq})}^{-} \rightarrow \mathrm{SrCO}_{3(\mathrm{~s})}+\mathrm{H}^{+} \\
& \mathrm{Sr}_{(\mathrm{aq})}^{2+}+\mathrm{CO}_{3(\mathrm{aq})}^{2-} \rightarrow \mathrm{SrCO}_{3(\mathrm{~s})}
\end{aligned}
$$

In one set of experiments, $0.5 \mathrm{~g}$ of $\mathrm{Na}_{2} \mathrm{CO}_{3}$ were added to the mixture of the $\mathrm{FA} / \mathrm{Sr}^{2+}$ solution (1:20 S/L ratio) and in a second set, air was bubbled through the same

Mixture of $\mathrm{FA} / \mathrm{Sr}^{2+}$ solution to dissolve $\mathrm{CO}_{2}$ from the air into the basic solution and in the third set, a combination of both the carbonate salt addition and air bubbling was performed. The samples were collected and processed for ICP analysis and the results are presented in Table 5.

At $\mathrm{pH} \sim 12.5$ the total concentration of $\mathrm{Sr}$ is expected to precipitate as $\mathrm{SrCO}_{3}$. Furthermore, the $\mathrm{SrCO}_{3}$ particles formed only under basic conditions in the absence of FA (Table 5, samples 7-9) pass through the $0.45-\mu \mathrm{m}$ Teflon filter and no apparent change in the solution $[\mathrm{Sr}]$ is detected.

The results in Table 5 indicate that in all the SAFA experiments no strontium ions are detected (within experimental error) in the analyzed extracted solutions. This indicates that all the $\mathrm{Sr}^{2+}$ ions were precipitated as an insoluble carbonate salt that either has a particle size greater than $0.45 \mu \mathrm{m}$ or that the particles formed adhered to the FA surface.

\section{Discussion}

Fundamentally, the ability of FA to serve as an efficient low-cost fixation material is attributed to the high concentration of alumina and silica functional groups present at the surface of the FA particles. The most abundant anionic groups at the surface are the silicates $\left(-\mathrm{O}-\mathrm{SiO}_{2}^{-}\right)$or the aluminates $\left(-\mathrm{O}-\mathrm{AlO}^{-}\right)$groups as can be observed in the EDAX analysis ( $\mathrm{Si}$ or $\mathrm{Al}$ ) presented in Fig. 1. Furthermore, the relatively large surface area $\left(>1 \mathrm{~m}^{2} / \mathrm{g}\right)$ of the FA particles was also determined to retain a significant negative charge in a basic solution (Fig. 2). These functional groups have different charges as a function of $\mathrm{pH}$ and can undergo interactions with ions through several reported mechanisms. In the current work it is apparent that there are 2 standard mechanisms involving the same functional groups at play for each of the different simulants. For the $\mathrm{Cs}^{+}$and the $\mathrm{Ce}^{3+/ 4+}$ ions the standard fixation models such as cation exchange or coordinative bonding are valid.

There is a pronounced difference between the fixation capability of the same FA substrate towards $\mathrm{Cs}^{+}$(Table 4) compared with $\mathrm{Ce}^{3+1}$ ${ }^{4+}$ ions (Table 3 ). Foremost, the interaction in both cases is concentration dependent and almost instantaneous. Surprisingly, while the initial concentration of both simulants is $\sim 20 \mathrm{ppm}$, it appears that the ability of the FA substrate to fixate cerium ions is greater. This can be assumed by the complete (within experimental error) fixation of the $\mathrm{Ce}^{3+/ 4+}$ ions vs. only $\sim 30 \%(0.31 \pm 0.11)$ of the $\mathrm{Cs}^{+}$ ions. However, the assumption that the surface functionalities responsible for this fixation effect are the same and remain constant suggests that different mechanisms are at play. One possible explanation for this difference could be explained by simply taking the ionic radii of the ions into consideration. The ionic radius of $\mathrm{Cs}^{+}$is $181 \mathrm{pm}$ (pico-meter, or $1.81 \AA$ ) as opposed to that of $\mathrm{Ce}^{3+/ 4+}$ which are considerably smaller with a, respectively, 115 and $101 \mathrm{pm}$ (or $1.15,1.01 \AA$ ). The respective size of the cesium ions are on average $\sim 68 \%$ larger than those of the cerium ions. This difference might perhaps explain the reduced capacitance of the FA. Although, the difference in bulk pH of the solution is a more likely candidate for these differences as a result of the changes in surface acidity (deprotonating - $\mathrm{XH}$ groups on the surface) affecting the available binding groups [45]. Obviously this is not an adequate explanation as one would expect that at a basic $\mathrm{pH}$ the fixation would increase (i.e. $\mathrm{Cs}^{+}$) while at the acidic $\mathrm{pH}$ (i.e. $\mathrm{Ce}^{3+/ 4+}$ ) the fixation would decrease as a result of a more significant change in the surface functionalities along the lines of the $\mathrm{pH}$ effect on the measured zeta potentials (Fig. 2).

It is likely that the fixation mechanism for each of the ions is different. $\mathrm{Cs}^{+}$is expected to interact with the FA surface in a cation exchange mechanism (Fig. 3A).

The $\mathrm{Ce}^{3+/ 4+}$ ions, due to their affinity to form complexes (as demonstrated by its rapid equilibrium and precipitation in water with $\mathrm{OH}^{-}$ions), are expected to undergo coordinative bonding with the non-bonding electrons of functional groups located at the surface of the FA particles (Fig. 3B):

Finally, as previously reported [45], for both types of FA up to $50 \%$ of the initial $\mathrm{Ca}^{2+}$, in addition to other cations such as $\mathrm{Sr}^{2+}$, leaches out in an acid solution as seem in the current work (Table 4).

As it is conceivable that all the above parameters have an effect on functional groups responsible for the FA fixation process, further experimentation taking these factors into consideration is clearly warranted.

Unsurprisingly, a similar fixation approach for aqueous $\mathrm{Sr}^{2+}$ was unsuccessful (Table 4) as the high concentration of inherent strontium in the FA ( 0.1-0.3 wt.\%, Table 1$)$ simply leached out to the bulk solution. In acidic environments, increased amounts of $\mathrm{Sr}^{2+}$ will leach out, resulting in more available Aluminate and Silicate groups on the surface, contributing to the fixation of $\mathrm{Ce}^{3+/ 4+}$.

Previously [46], the adsorption characteristics of the strontium and cesium nuclides onto kaolinite, a layered silicate mineral, were investigated by batch experiments under various $\mathrm{pH}$ conditions and concentrations of groundwater cations. It was reported that the $\mathrm{pH}$ exerted a small effect on the adsorption of the ions onto kaolinite while the zeta potential of kaolinite particles showed a negative increase of amphoteric surface charge with increasing $\mathrm{pH}$. Of particular interest was the determination that the adsorption behavior of strontium cations is highly dependent on the concentration of bicarbonate in solution. The thermodynamic saturation index indicated that bicarbonate exerted a great effect 


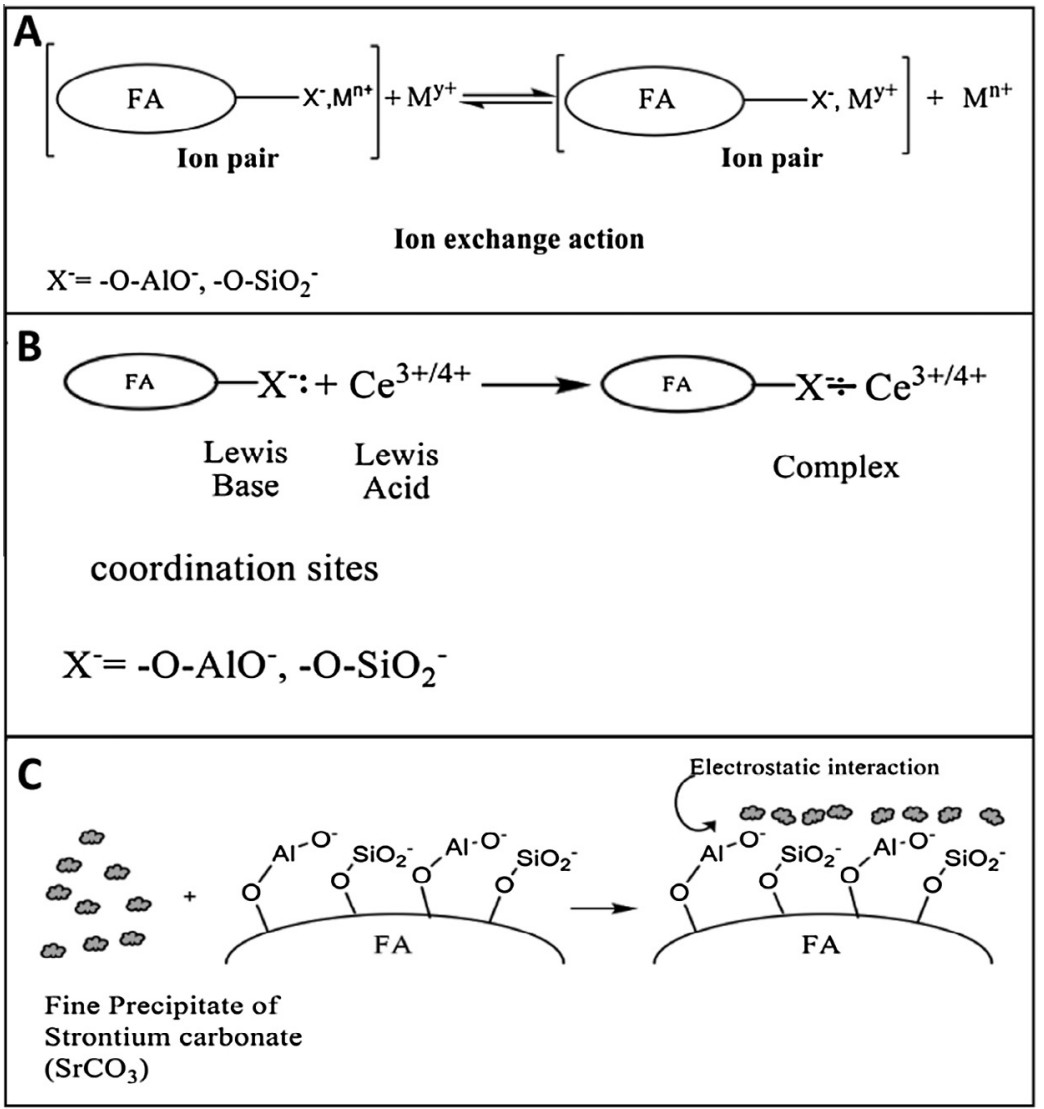

Fig. 3. FA fixation mechanisms: (A) cation exchange reagent, $(\mathrm{B})$ coordinative bonding reagent, $(\mathrm{C})$ precipitation of $\mathrm{SrCO}_{3}$ via the $\mathrm{FA}$ at $\mathrm{pH}>10.5$.

on strontium adsorption by the precipitation of a strontianite $\left(\mathrm{SrCO}_{3}\right)$ and a change in $\mathrm{pH}$.

Utilizing the reported carbonate effect, a new method was developed to avoid this leaching effect of the inherent $\mathrm{Sr}^{2+}$ from FA. The two approaches attempted, $\left(\mathrm{CO}_{2(\mathrm{~atm})}, \mathrm{Na}_{2} \mathrm{CO}_{3(\mathrm{~s})}\right)$, for increasing the $\left[\mathrm{CO}_{3}^{2-}\right]$ were found to be equally sufficient to saturate the system and precipitate the $\mathrm{Sr}^{2+}$ as a carbonate salt. The results indicated (Table 5) that in all the FA experiments no strontium ions are left (within experimental error) in the analyzed extracted solutions. This indicates that all the $\mathrm{Sr}^{2+}$ ions were precipitated as an insoluble carbonate salt with either an increased diameter $>0.45-\mu \mathrm{m}$ (with the FA acting as a growth catalyst) or alternatively adherence to the FA surface. It is important to state that as Table 5 demonstrated that in the absence of $\left[\mathrm{CO}_{3}^{2-}\right]$ inherent $\mathrm{Sr}^{2+}$ undergoes dissolution [Sr] $]_{0}$ is conceivably higher than the $20 \mathrm{ppm}$ introduced. Therefore, the fact that the 'real' fixation concentration under these conditions is higher than $[\mathrm{Sr}]_{0}$, along with a negligible detection in the leach solution, demonstrates that FA effectively retains the strontium in this novel method.

In light of the fact that, in the absence of FA, no measurable change in $\left[\mathrm{Sr}^{2+}\right]$ is observed indicates that $\mathrm{SrCO}_{3}$ is not formed and supports the claim that the $\mathrm{SrCO}_{3}$ formed is indeed fixed on the surface of the FA. One plausible explanation for the fixation is that the presence of the FA serves as a growth catalyst, generating bigger particles that precipitate more efficiently. Alternatively, as the surface is negatively charged at basic $\mathrm{pH}$, particles with a positive charge will be drawn to the surface of the FA. As it has been reported that the $\mathrm{SrCO}_{3}$ particles have a positive zeta potential $[18,46,47]$, it is suggested that this is the primary fixation pathway. The electrostatic interaction of the $\mathrm{SrCO}_{3}$ particles with the FA surface is presented in Fig. $3 \mathrm{C}$. No $\mathrm{SrCO}_{3}$ could be detected by the SEM-EDAX analysis, due to the low concentration of $\mathrm{Sr}^{2+}$ $(\sim 10 \mathrm{ppm})$ in the mother solution.

\section{Conclusions}

The results of this study demonstrate that Class F fly ashes such as SAFA and COFA can potentially serve as a cheap ( $\leqslant 15 \$ /$ ton ) partial substitute for the fixation of radioactive nucleotides.

The fixation properties of the fly ash are attributed to the presence of $-\mathrm{AlO}_{2}^{-}$and $-\mathrm{SiO}_{3}^{-}$at the aluminosilicate glassy phase. These groups likely undergo coordinative interactions with $\mathrm{Ce}^{3+/ 4+}$ vs. cation exchange interactions with $\mathrm{Cs}^{+}$.

A novel method for the utilization of the negatively charged surface of the FA towards the retention of positively charged particles has been developed and its feasibility was demonstrated for $\mathrm{SrCO}_{3}$.

The current findings suggest that Class F FA can conceivably retain more than one type of simulant by utilizing multiple fixation mechanisms in parallel (e.g. cation exchange interactions with cesium while precipitating strontium as $\mathrm{SrCO}_{3}$ ).

\section{Acknowledgements}

The authors thank the Israel Coal Ash Administration for funding the research and the Ariel University for the workspace. Dr. Hanan Teller provided significant support in maintaining the facilities and Ms. Natali Litbek the SEM analysis.

Additionally, the Israel Geological Survey is thanked for their assistance with the elemental analysis and Prof. Xavier Querol 
along with Dr. Oriol Font from the CSIC \& IDAEA institute in Barcelona, Spain for the XRD analyses.

Finally, the authors particularly thank Dr. Eyal Elish and Dr. Eitan J.C. Borojovich from the NRCN (Nuclear Research Center Negev, Beer Sheva Israel) for the ICP and Ion Chromatography analysis.

\section{Appendix A. Supplementary material}

Supplementary data associated with this article can be found, in the online version, at http://dx.doi.org/10.1016/j.fuel.2015.02.111.

\section{References}

[1] The Israel Electric Corp. <http://www.iec.co.il>; 2014 [accessed 10.12.14].

[2] National Coal Ash Board, Israel, General info. <http://www.coal-ash.co.il/ english/info>; 2013 [accessed 10.12.14].

[3] Israel ministry of environmental protection, abatement of nuisances regulations (Air Quality), 5752-1992. In: Israel ministry of environmental protection, (Ed.); 1992. p. 5.

[4] The national coal supply corporation LTD. <http://ncsc.co.il>. The coals undergo beneficiation via washing appreciable amount of minerals and reducing its' content to $\sim 10 \%$ (from $\sim 20 \%$ in untreated coal), 2013 [accessed 30.12.14].

[5] Ahmaruzzaman M. A review on the utilization of fly ash. Prog Energy Combust Sci 2010;36:327-63.

[6] Arivazhagan K, Ravichandran M, Dube S, Mathur V, Khandakar R, Yagnanarayana K, Kamal Pasha M, Sinha A, Sarangi B, Tripathi V. Effect of coal fly ash on agricultural crops: showcase project on use of fly ash in agriculture in and around thermal power station areas of National Thermal Power Corporation Ltd., India. In: World of Coal Ash Conference, Denver (CO); 10-12 May 2011. p. 9-12 <http://www.worldofcoalash.org/2011/ashpdf/ a016-Arivazhagan-2011.pdf>.

[7] Basu M, Pande M, Bhadoria P, Mahapatra S. Potential fly-ash utilization in agriculture: a global review. Prog Nat Sci 2009;19:1173-86.

[8] Berndt M. Properties of sustainable concrete containing fly ash, slag and recycled concrete aggregate. Constr Build Mater 2009;23:2606-13.

[9] Ramseyer CC, Kiamanesh R. Optimizing concrete mix designs to produce cost effective paving mixes. In: University of Oklahoma; 2009. p. 122.

[10] Fatih T, Umit A. Utilization of fly ash in manufacturing of building bricks. In: International ash utilization symposium. Center for applied energy research, University of Kentucky, Lexington (KY), Paper 13; 22-24 October $2001<w w w$. flyash.info>.

[11] Foner H, Robl T, Hower J, Graham U. Characterization of fly ash from Israel with reference to its possible utilization. Fuel 1999;78:215-23.

[12] Iyer R, Scott J. Power station fly ash-a review of value-added utilization outside of the construction industry. Resour, Conserv Recycling 2001;31:217-28

[13] Joshi RC, Lohita R. Fly ash in concrete: production, properties and uses. CRC Press; 1997.

[14] Kayali O. High performance bricks from fly ash. In: Proceedings of the world of coal ash conference, Lexington (KY); 11-15 April 2005. <http://www.flyash. info>.

[15] Nathan Y, Deutsch Y. Workshop on environmental and health aspects of coal ash utilization, Tel Aviv, Israel; 23-24 November 2005. <http://www.coal-ash. co.il/sadna/Abstract\%20_Nathan.pdf>.

[16] Cohen H. Fly ash: a potential excellent scrubber for acidic wastes in Israel. In: International ash utilization symposium, center for applied energy research. University of Kentucky; 2003.

[17] Lederman E. Coal fly ash as a chemical reagent for scrubbing industrial acidic waste. In: Chemistry, Ben Gurion University, thesis; 2008.

[18] Polat M, Guler E, Lederman E, Cohen H. Neutralization of an extremely acidic sludge and stabilization of heavy metals in flyash aggregates. Waste Manage 2007;27:482-9.

[19] Polat M, Lederman E, Pelly I, Cohen H. Chemical neutralization of acidic wastes using fly ash in Israel. J Chem Technol Biotechnol 2002;77:377-81.
[20] Bayat B. Combined removal of zinc (II) and cadmium (II) from aqueous solutions by adsorption onto high-calcium Turkish fly ash. Water, Air, Soil Pollut 2002;136:69-92.

[21] Hequet V, Ricou P, Lecuyer I, Le Cloirec P. Removal of $\mathrm{Cu}^{2+}$ and $\mathrm{Zn}^{2+}$ in aqueous solutions by sorption onto mixed fly ash. Fuel 2001;80:851-6.

[22] Kanungo S, Mohapatra R. Leaching behavior of various trace metals in aqueous medium from two fly ash samples. J Environ Qual 2000;29:188-96.

[23] Wang S, Viraraghavan T. Wastewater sludge conditioning by fly ash. Waste Manage 1998;17:443-50.

[24] Rodgers M, Armentrout P. Noncovalent metal-ligand bond energies as studied by threshold collision-induced dissociation. Mass Spectrom Rev 2000;19: 215-47.

[25] European Committee for Standardization. Compliance test for leaching of granular waste materials and sludges (EN12457-2), 2003.

[26] US Environmental Protection Agency (EPA). Toxicity Characteristic Leaching Procedure (TCLP) - Method 1311; 1992.

[27] California department of toxic substances control, control, California Waste Extraction Test (CAL WET): environmental health standards - hazardous waste, 66261.126 Appendix II., 2005.

[28] Ministry of health. Drinking water regulations. <http://www.health.gov.il/ Subjects/Environmental_Health/drinking_water/Documents/Briut47-Eng.pdf>; 2013 [accessed 10.13.14].

[29] World nuclear association, radioactive waste management. <http:/ www.world-nuclear.org/info/Nuclear-Fuel-Cycle/Nuclear-Wastes/ Radioactive-Waste-Management/>; 2013 [accessed 05.12.14].

[30] US Environmental Protection Agency (EPA), Strontium. <http://www.epa.gov/ radiation/radionuclides/strontium.html>; 2012 [accessed 05.12.14].

[31] US Environmental Protection Agency (EPA), Cesium. <http://www.epa.gov/ radiation/radionuclides/cesium.html>; 2013 [accessed 05.12.14].

[32] National library of medicine, strontium, radioactive. <http://toxnet.nlm.nih.gov/ cgi-bin/sis/search/r?dbs+hsdb:@term+@na+@rel+strontium,+radioactive>; 2004 [accessed 15.07.14].

[33] Okumura T. The material flow of radioactive Cesium-137 in the US 2000 United States Environmental Protection Agency. <http://earth1.epa.gov/ radiation/docs/source-management/csfinallongtakeshi.pdf>; 2014 [accessed 15.12.14].

[34] Wilson PD. The nuclear fuel cycle. Oxford: Oxford University Press; 1996.

[35] US Environmental Protection Agency (EPA), Plutonium. <http://www.epa.gov/ radiation/radionuclides/plutonium.html>; 2012 [accessed 15.12.14].

[36] Nathan Y, Dvorachek M, Pelly I, Mimran U. Characterization of coal fly ash from Israel. Fuel 1999;78:205-13.

[37] Fenelonov V, Mel'gunov M, Parmon V. The properties of cenospheres and the mechanism of their formation during high-temperature coal combustion at thermal power plants. KONA Powder Part J 2010;28:189-208.

[38] Sear LK. Properties and use of coal fly ash: a valuable industrial byproduct. London (UK): Thomas Telford Ltd; 2001.

[39] Vassilev SV, Menendez R, Alvarez D, Diaz-Somoano M, Martinez-Tarazona MR. Phase-mineral and chemical composition of coal fly ashes as a basis for their multicomponent utilization. 1. Characterization of feed coals and fly ashes. Fuel 2003;82:1793-811.

[40] Ghosal S, Self SA. Particle size-density relation and cenosphere content of coal fly ash. Fuel 1995;74:522-9.

[41] Grossman NY, Mathews A. The mineralogy and chemistry of coal ash generated by the Hadera M.D. power station. J Coal Qual 1988;7:22-6. S.L..

[42] Lieberman RN, Lederman E, Pelly I, Cohen H. Fly ash as a potential scrubber of acidic wastes from the phosphate industries in Israel. Coal Combust Gasification Prod 2014:6:7-15

[43] Bouchaud B, Balmain J, Bonnet G, Pedraza F. PH-distribution of cerium species in aqueous systems. J Rare Earths 2012;30:559-62.

[44] Dean JA. Lange's handbook of chemistry. 15th ed. USA: McGraw-Hill; 1999.

[45] Lieberman RN, Teutsch N, Cohen H. Chemical and surface transformations of bituminous coal fly ash used in Israel following treatments with acidic and neutral aqueous solutions. Energy Fuels 2014;28(7):4657-65.

[46] Jeong $\mathrm{CH}$. Mineralogical and hydrochemical effects on adsorption removal of cesium-137 and strontium-90 by kaolinite. J Environ Sci Health, Part A 2001;36:1089-99.

[47] Sondi I, Bišćan J, Vdović N, Škapin SD. The electrokinetic properties of carbonates in aqueous media revisited. Colloids Surf A: Physicochem Eng Aspects 2009;342:84-91. 